\title{
Overexpression of phosphorylated nuclear factor-kappa B in tonsillar squamous cell carcinoma and high-grade dysplasia is associated with poor prognosis
}

Ping L Zhang ${ }^{1,4}$, Phillip K Pellitteri², Amy Law ${ }^{3}$, Patricia A Gilroy ${ }^{2}$, G Craig Wood ${ }^{4}$, Thomas L Kennedy ${ }^{2}$, Thomas M Blasick ${ }^{4}$, Mingyue Lun ${ }^{4}$, Conrad Schuerch III ${ }^{1}$ and Robert E Brown ${ }^{1}$

${ }^{1}$ Division of Laboratory Medicine, Geisinger Medical Center, Danville, PA, USA; ${ }^{2}$ Head and Neck Surgery Department, Geisinger Medical Center, Danville, PA, USA ${ }^{3}$ Adult Hematology/Oncology Department, Geisinger Medical Center, Danville, PA, USA and ${ }^{4}$ Weis Center for Research, Geisinger Medical Center, Danville, PA, USA

\begin{abstract}
Intracellular signals along the epidermal growth factor receptor (EGFR)-Akt-nuclear factor-kappa B (NF- $k$ B) pathway have been associated with carcinogenesis in various malignant neoplasms. This investigation was to evaluate the expression of EGFR, phosphorylated(p)-Akt and $p-N F-\kappa B$ and correlate them with clinical outcomes in patients with squamous cell carcinoma of the tonsil. A total of 45 patients with squamous cell carcinoma of the tonsil were studied by immunohistochemistry to evaluate the expression levels of EGFR, p-Akt and $p-N F-\kappa B$. Results for squamous cell carcinoma of the tonsil were compared with those for associated highgrade dysplasia and adjacent normal appearing epithelium, when present. In addition, tonsillar epithelium from non-neoplastic specimens of age-matched patients also was stained for the same markers. High-grade dysplasia and squamous cell carcinoma of the tonsil demonstrated a similar pattern of expression, which differed from the pattern seen in the adjacent normal epithelium and tonsillar epithelium from normal controls (an overexpression for each of these three protein analytes in high-grade dysplasia and squamous cell carcinoma of the tonsil as demonstrated by immunohistochemistry). When markers from squamous cell carcinoma of the tonsil were correlated with survival status, only increasing levels of p-NF- $\kappa$ B immunoreactivity (a relative overexpression) were statistically significant predictors of poor survival. No markers in squamous cell carcinoma of the tonsil were significantly related to rate of recurrence. When analyzing marker scores from tissue with high-grade dysplasia, relative overexpressions of both p-Akt and p-NF- $\kappa$ B were significantly related to poor survival. Additionally, increasing levels of $p-N F-k B$ immunopositivity from tissue with high-grade dysplasia were also significantly related to rate of recurrence. In summary, $p-N F-k B$, overexpressed in highgrade dysplasia and squamous cell carcinoma of the tonsil, is associated with worse prognosis in terms of high recurrence and poor survival, respectively. This significant finding in patients with squamous cell carcinoma of the tonsil, in combination with previous animal and in vitro studies, suggests that p-NF- $\kappa$ B represents a potential therapeutic target in head and neck squamous cell carcinoma.
\end{abstract}

Modern Pathology (2005) 18, 924-932. doi:10.1038/modpathol.3800372; Published online 6 May 2005

Keywords: head and neck squamous cell carcinoma; molecular pathways; morphoproteomics; nuclear factorkappa B; prognosis

Upregulation of epidermal growth factor receptors (EGFR) has been found in many types of malignant tumors. Enzyme immunoassay has revealed that

Correspondence: Dr RE Brown, MD, Division of Laboratory Medicine, Geisinger Medical Center, Danville, PA 17822-0131, USA.

E-mail: rebrown@geisinger.edu

Received 5 October 2004; revised and accepted 29 November 2004; published online 6 May 2005
EGFR overexpression in head and neck squamous cell carcinoma is found in $58 \%$ of cases and carries a statistical association with poor survival and TNM stage. ${ }^{1}$ Immunohistochemical demonstration of EGFR overexpression in head and neck squamous cell carcinoma has been correlated with a high mitotic index and advanced (stage III and IV) tumors. $^{2}$ In a phase II clinical trial in refractory head and neck squamous cell carcinoma, ZD1839 (Iressa), targeted at EGFR, had single-agent activity 
with a $10.6 \%$ response rate and a disease control rate of $53 \%$ and was well tolerated. ${ }^{3}$ The downstream signals of EGFR such as ras protein (activated through farnesyl transferase), Akt and nuclear factor-kappa $\mathrm{B}(\mathrm{NF}-\kappa \mathrm{B})$ all may be related to the tumorigenesis of head and neck squamous cell carcinoma. $^{4-7}$ Importantly, two gene microarray studies in head and neck squamous cell carcinoma cell lines or animal models with head and neck squamous cell carcinoma provide evidence that NF$\kappa \mathrm{B}$ gene is upregulated. ${ }^{8,9}$ However, it is unclear whether there is concurrent overexpression of potentially related markers such as EGFR and phosphorylated (activated) forms of Akt and NF- $\kappa \mathrm{B}$ in head and neck squamous cell carcinoma, and secondly whether they may be associated with poor clinical outcome.

Kinases are critical enzymes in essentially every aspect of cell physiology, which through phosphorylation enable rapid cellular changes in response to environmental and cellular alterations. ${ }^{10,11}$ Intracellular signal transduction is mediated in large part by kinase cascades that propagate, amplify and expand signaling networks. Phosphorylation serves to transduce these signals and dynamically regulates enzymatic activity and protein interactions. The central role of kinases in cellular regulation is reflected in the fact that abnormalities in kinase pathway activity have been implicated in an array of human diseases and in particular, malignant tumors. ${ }^{12,13}$ Dysregulated phosphorylation by an activated oncogene protein is a common mechanism of malignant transformation and tumorigenesis. ${ }^{12-14}$

In this investigation, a semiautomatic immunohistochemical technique was developed to stain phosphorylated signal transduction proteins with a minimal staining background to facilitate visual quantification and cellular compartmentalization of the activated protein (morphoproteomics). We found that EGFR, phosphorylated (p)-NF- $\kappa$ B and pAkt were overexpressed in terms of immunoreactivity for these protein analytes in squamous cell carcinoma of the tonsil and associated high-grade dysplasia, when compared to controls. More importantly, increasing immunohistochemical scores for $\mathrm{p}-\mathrm{NF}-\kappa \mathrm{B}$ (relative overexpressions) were found to convey predictive value for poor survival in squamous cell carcinoma of the tonsil. In high-grade dysplasia, both $\mathrm{p}-\mathrm{Akt}$ and $\mathrm{p}-\mathrm{NF}-\kappa \mathrm{B}$ overexpressions were statistically and independently associated with poor survival and in addition, $\mathrm{p}-\mathrm{NF}-\kappa \mathrm{B}$ was related to rate of recurrence.

\section{Materials and methods}

\section{Patients and Immunohistochemistry for Ki-67 and EGFR}

In this study, we focused on patients with squamous cell carcinoma of the tonsil and retrospectively identified forty-five (45) such patients followed within the period from 1998 to 2003 at the Geisinger Medical Center. Archival tissue blocks were retrieved for the analysis. A total of 41 patients undergoing tonsillectomy for nontumoral indications were selected as age-matched controls. Antibodies for Ki-67 and EGFR (PharmDx) were obtained from DAKO Cooperation (Carpinteria, CA, USA). Both p-Akt antibody (serine 473) and p-NF- $\kappa$ B antibody (p-p65, serine 536) were purchased from Cell Signaling Technology, Inc. (Beverly, MA, USA). Paraffin blocks were selected for immunohistochemical staining, in order to identify normal epithelium, high-grade dysplasia and invasive cancer on the same sections, whenever possible. Tissue blocks for tonsillar controls were punctured in constructing a tissue microarray block ( $0.6 \mathrm{~mm}$ in diameter each), using a manual arrayer from Beecher Instruments (Sun Praivie, WI, USA). The tissue block was cut into $5-\mu \mathrm{m}$ sections and sections were dewaxed in xylene and rehydrated with graded ethanols to water. Subsequently slides were stained immunohistochemically for either Ki-67 or EGFR, using DAKO Autostainer (Model E172566) (Carpinteria, CA, USA).

\section{Semiautomatic Immunohistochemical Staining for $p-A k t$ and $p-N F-\kappa B$}

To minimize the staining background using antibodies against p-Akt and p-NF- $\kappa \mathrm{B}$, a semiautomatic method for phosphorylated protein antibodies was developed. Paraffin-embedded tissues were sectioned and placed on glass slides, and dried at $60^{\circ} \mathrm{C}$ for $1-2 \mathrm{~h}$. Next, they were deparaffinized and underwent antigen retrieval. Slides were placed in a $0.1 \mathrm{M}$ citric acid (Sigma-Aldrich), 0.1 M sodium citrate (Fisher) solution and heated in a microwave until the solution reaches boiling. Once boiling was reached, the slides were heated for $10 \mathrm{~min}$, followed by a 20 min cooling period outside the microwave. The slides were then placed in $0.05 \mathrm{M}$ Tris- $\mathrm{HCl}$, $0.05 \%$ Tween-20 (TBST buffer) for $5 \mathrm{~min}$ (Tris-HCl in packs from Dako Cytomation, Tween-20 from EM Science). The tissue was then treated with $3 \% \mathrm{H}_{2} \mathrm{O}_{2}$ (McKesson General Medical) for $5 \mathrm{~min}$, and then rinsed with TBST buffer. A few drops of diluted normal blocking serum (Vectastain kit, Vector Laboratories) were placed on the tissue and incubated at room temperature for $1 \mathrm{~h}$. The serum was then carefully blotted off and the slides were incubated with primary antibody overnight at $4^{\circ} \mathrm{C}$. The following day, the tissues were rinsed well with TBST buffer for a minimum of $5 \mathrm{~min}$. The rest of the staining procedure took place on a DAKO Autostainer. The machine was programmed to treat each slide with diluted biotinylated secondary antibody solution (Vectastain Kit) for $30 \mathrm{~min}$. The slides were rinsed with TBST buffer and incubated with Vectastain Elite Antigen Binding Complex Reagent (Vectastain Kit) for $30 \mathrm{~min}$. The slides were rinsed 
with TBST buffer and incubated with DAB solution (3,3'-diaminobenzidine chromogen solution, DAKO EnVision + System Kit) for $10 \mathrm{~min}$. The slides were then removed from the autostainer and rinsed with distilled water. They were then counterstained with Gill II Hematoxylin (Thermo Shandon) for $20 \mathrm{~s}$, treated with xylene (Fisher) for $10-15 \mathrm{~s}$ and coverslipped.

\section{Evaluation of Immunohistochemical Staining}

High-grade dysplasia is characterized by a full thickness of atypical proliferative epithelium while normal squamous epithelium preserves active proliferation at the lower basal/suprabasal layers. We found that the greatest differences in staining pattern for all markers between normal squamous epithelium and high-grade dysplasia was within the top $1 / 3$ of squamous epithelium. For the top $1 / 3$ of normal epithelium, the top $1 / 3$ of high-grade dysplasia and invasive cancer, the staining intensity score was graded from 0 to $3+(0-$ no staining, $1+$ -weak staining, $2+-$ moderate staining and $3+-$ strong staining). In addition, the percent of total area staining was also estimated. The combined score was calculated using intensity score times the percent of stained cells. In two previous studies, we found this method of evaluating staining matched very well with the scoring system generated by the ChromaVision Automated Cellular Imaging System. ${ }^{15,16}$

\section{Statistical Methods}

Clinical data from these patients were collected through Geisinger Health Systems electronic health record (Epicare) and linked to immunohistochemistry data. The clinical data included age, gender, history of smoked/smokeless tobacco, TNM status, stage (I-IV), recurrence and survival. The clinical profiles of the squamous cell carcinoma and control patients were compared using $t$-tests and $\chi^{2}$ tests as appropriate. Staining intensity score and positively stained percentage was recorded in each group as mean \pm s.d. Combined score was calculated using stained intensity score multiplying positively stained percent. A one-way analysis of variance (ANOVA) was used to detect overall differences between means of each group. Pair-wise comparisons between groups were conducted while adjusting for multiple comparisons using the Bonferroni method. Further analyses were conducted to determine if significant univariate relationships exist after controlling for age, gender, tobacco use and alcohol use. Overall survival and recurrence rates were summarized using Kaplan-Meier survival curves. The scores of markers from squamous cell carcinoma of the tonsil and high-grade dysplasia tissues were correlated to survival and recurrence using Cox regression. Prior to regression analysis, the combined scores (which ranged from 0 to 300 ) were transformed into $0,1+, 2+$, and $3+$. Statistical analysis and data manipulations were conducted using SAS (Statistical Analysis Systems 8.1, Cary, NC, USA). The Kaplan-Meier survival curves were created using S-PLUS 2000 (Mathsoft, Inc., Cambridge, MA, USA). All $P$-values were twosided and those less than 0.05 were considered statistically significant.

\section{Results}

\section{Clinical Profiles of Patients with Squamous Cell Carcinoma of the Tonsil and Tonsillar Controls Patients}

There were a total of 86 study subjects included in the analysis, of which 45 had squamous cell carcinoma of the tonsil and 41 were controls. A comparison of the characteristics of the study populations is detailed in Table 1. A history of tobacco use correlated significantly with squamous cell carcinoma of the tonsil $(82 \%$ in squamous cell carcinoma of the tonsil group vs 61\% in control group, $P=0.028$ ). No significant differences in age, gender and history of alcohol use were observed between patients with squamous cell carcinoma of the tonsil and the control group.

Follow-up periods were available for 41 patients with squamous cell carcinoma of the tonsil. Of 41 patients, 15 died of disease. In all, 30 patients were evaluable for tumor recurrence. Six had disease recurrence. Of those six patients, two patients had distant disease, with liver, lung as sites of disease failure. Two patients had local disease progression. Two patients had second head and neck primaries (base of tongue (2) and larynx (1)). Kaplan-Meier disease-free survival curve (Figure 1, upper panel) and recurrence-free survival curve (Figure 1, lower

Table 1 Comparison of characteristics of tonsillar squamous cell carcinoma (SCC) and control populations

\begin{tabular}{|c|c|c|c|}
\hline & $S C C$ & Controls & $\mathrm{P}$-value \\
\hline \multicolumn{4}{|l|}{$N$} \\
\hline Sample size & 45 & 41 & \\
\hline \multicolumn{4}{|l|}{ Age (years) } \\
\hline Mean (s.d.) & $59(11)$ & $55(7)$ & $0.078^{\mathrm{a}}$ \\
\hline \multicolumn{4}{|l|}{ Gender } \\
\hline Male (\%) & $29(64 \%)$ & $33(83 \%)$ & $0.062^{\mathrm{b}}$ \\
\hline \multicolumn{4}{|l|}{ Tobacco } \\
\hline Current (\%) & $20(44 \%)$ & $11(27 \%)$ & $0.089^{\mathrm{b}}$ \\
\hline Ever (\%) & $37(82 \%)$ & $25(61 \%)$ & $0.028^{\mathrm{b}}$ \\
\hline \multicolumn{4}{|l|}{ Alcohol } \\
\hline Current (\%) & $22(49 \%)$ & $25(61 \%)$ & $0.26^{\mathrm{b}}$ \\
\hline Ever (\%) & $34(76 \%)$ & $26(63 \%)$ & $0.22^{\mathrm{b}}$ \\
\hline
\end{tabular}



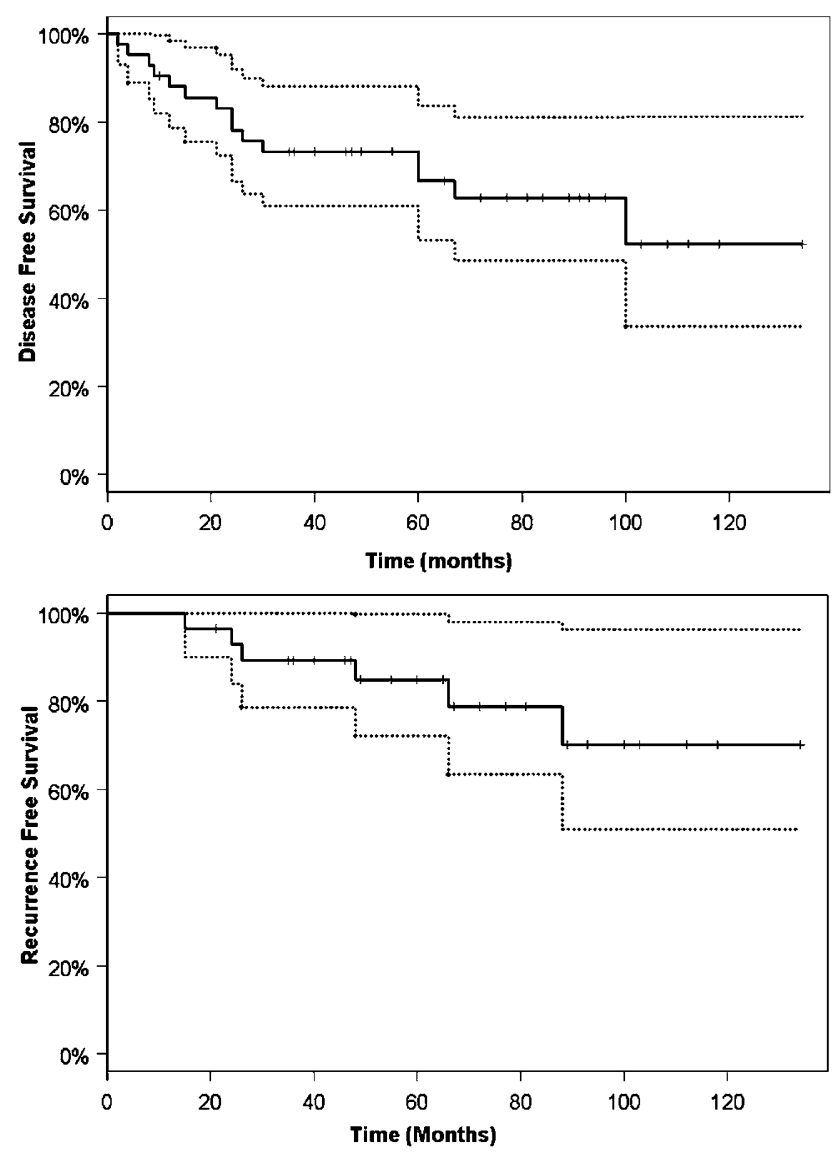

Figure 1 Disease-free survival curve (\%) $(n=41$, subjects with squamous cell carcinoma; upper panel) and recurrence-free survival curve (\%) $(n=29$, subjects with squamous cell carcinoma; lower panel). The dashed lines in both panels represent $95 \%$ confidence intervals.

panel) were constructed for all patients with squamous cell carcinoma of the tonsil (the dashed lines represent 95\% confidence intervals). Event rates for died of disease and recurrence at 1, 3, 5 and 10 years are listed in Table 2.

Statistical analysis of TNM and stage vs outcome revealed the following: (1) high tumor (T) scores may be related to decreased survival (hazard rate $=1.54, P=0.06$ ); (2) no relationship between $\mathrm{T}$ scores and recurrence (hazard rate $=1.62, P=0.22$ ); (3) nodal status (N) was not significantly related to overall survival (hazard rate $=1.52, P=0.27$ ) or recurrence (hazard rate $=0.65, P=0.35$ ); (4) metastasis (M) was not evaluable since cell values were equal to ' 0 '; and (5) stage was not significantly related to overall survival (hazard rate $=0.87$, $P=0.60$ ) or recurrence (hazard rate $=0.72, P=0.41$ ).

\section{Evaluation of Marker Expression Scores between Groups (Control, Benign, High-Grade Dysplasia, Squamous Cell Carcinoma of the Tonsil)}

Plasmalemmal staining of EGFR and predominant nuclear staining of $\mathrm{p}-\mathrm{NF}-\kappa \mathrm{B}$ from one patient with all three components (non-neoplastic squamous
Table 2 Event rates at 1, 3, 5 and 10 years in tonsillar SCC patients

\begin{tabular}{lcccc}
\hline Event & 1-year & 3 -year & 5 -year & 10 -year \\
\hline $\begin{array}{l}\text { Died of disease } \\
\text { Rate }\end{array}$ & $12 \%$ & $27 \%$ & $33 \%$ & $48 \%$ \\
$95 \%$ CI & {$[2 \%, 21 \%]$} & {$[12 \%, 39 \%]$} & {$[16 \%, 47 \%]$} & {$[19 \%, 66 \%]$} \\
& \multicolumn{4}{c}{} \\
$\begin{array}{l}\text { Recurrence } \\
\text { Rate }\end{array}$ & $0 \%$ & $11 \%$ & $15 \%$ & $30 \%$ \\
$95 \%$ CI & NA & {$[0 \%, 21 \%]$} & {$[0 \%, 28 \%]$} & {$[4 \%, 49 \%]$} \\
\hline
\end{tabular}

epithelium, high-grade dysplasia and squamous cell carcinoma of the tonsil) are illustrated in Figure 2. The top 1/3 of normal epithelium was not stained either for EGFR and minimally for p-NF- $\kappa \mathrm{B}$, although epithelial cells of proliferative suprabasal layers in the lower $2 / 3$ were stained for both EGFR and $\mathrm{p}-\mathrm{NF}-\kappa \mathrm{B}$. These expressions coincided with the Ki-67 immunopositivity in the immediate suprabasal layers and are consistent with the putative role of such layers in physiologic renewal and integrity of the mucosal epithelium. ${ }^{17}$ In contrast, high-grade dysplasia showed strong staining for both EGFR and p-NF- $\kappa$ B all the way to the surface of the epithelium, with nuclear atypia. Squamous cell carcinoma of the tonsil also revealed strong staining for both EGFR and $\mathrm{p}-\mathrm{NF}-\kappa \mathrm{B}$ similar to high-grade dysplasia. Scores of the several markers were compared between tonsil squamous epithelium from patients without cancer (tonsil controls), benign squamous epithelium from patients with cancer (benign), high-grade dysplasia and squamous cell carcinoma of the tonsil (Table 3). For all four markers, there was no difference in the pattern of staining between benign appearing epithelium adjacent to cancer and benign tonsillar controls; and between high-grade dysplasia and squamous cell carcinoma of the tonsil. In both high-grade dysplasia and squamous cell carcinoma of the tonsil, the staining intensity, staining percent and combined scores from all four markers were significantly higher when compared with control tonsils and benign appearing epithelium. Table 4 lists the percent distribution of intensity scores for all four markers in the four groups. There were high percents of strong staining $(2+$ and $3+)$ for all four markers in high grade dysplasia and squamous cell carcinoma of the tonsil, whereas the majority of cases from either benign appearing epithelium adjacent to cancer or benign tonsillar controls had 0 to $1+$ staining for the four markers.

\section{Correlation of Cancer Marker Score to Outcomes}

There were no significant relationships between Ki-67, EGFR and p-Akt expressions and survival or rate of recurrence. There was a significant relationship between p-NF- $\kappa$ B immunoreactivity and survival. An increase in one level of score, such as from $1+$ to $2+$, decreased the chance of survival by 

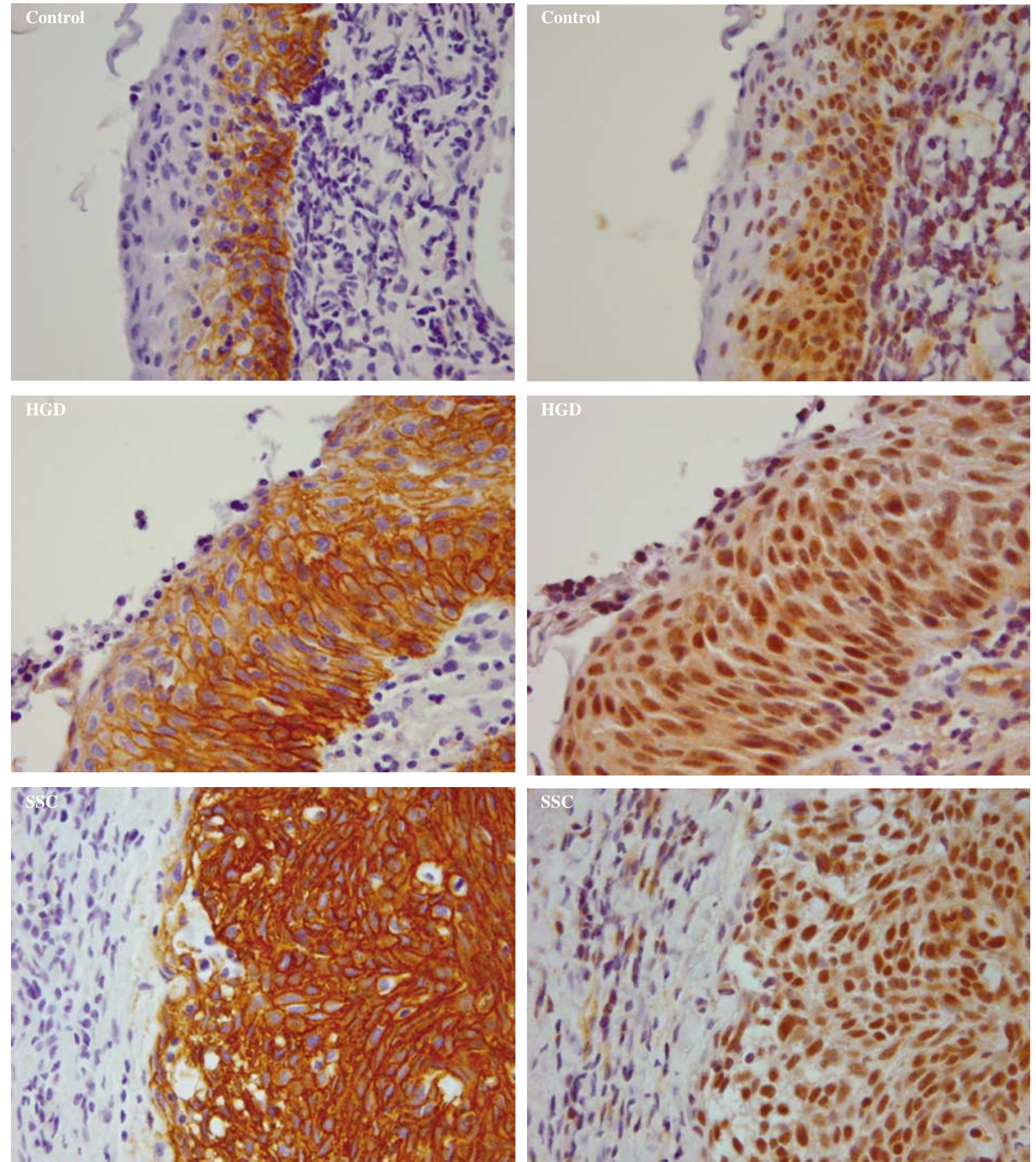

Figure 2 Plasmalemmal expression of EGFR in normal appearing tonsillar squamous epithelium (control, at left upper panel), high-grade dysplasia (HGD, at left mid-panel) and tonsillar squamous cell carcinoma (SCC, at left lower panel); corresponding nuclear expression of p-NF- $\kappa$ B in normal appearing squamous epithelium (control, at right upper panel), HGD (at right mid panel) and SCC (at right lower panel) (magnification $\times 600$ ).

2.0-fold (hazard rate $=2.0,95 \% \mathrm{CI}=[1.0,4.0]$, $P=0.047)$. The upper panel of Figure 3 contrasts weak $(1+)$ and strong $(3+)$ nuclear staining of $\mathrm{p}-\mathrm{NF}-\kappa \mathrm{B}$ in different squamous cell carcinoma of the tonsil and the lower panel of Figure 3 presents the disease-free survival curve stratified by $p-N F-\kappa B$ level. We did not observe a significant relationship between $\mathrm{p}-\mathrm{NF}-\kappa \mathrm{B}$ and the rate of tumor recurrence.

\section{Correlation of High-Grade Dysplasia Marker Score to Outcomes}

This analysis was limited to the 26 subjects with high-grade dysplasia. Neither Ki-67 nor EGFR expression in tissues with high-grade dysplasia correlates with survival and tumor recurrence. A statistically significant relationship was observed 
Table 3 Comparison of scores of several markers in tonsillar squamous epithelium from patients without cancer (tonsil controls), benign squamous epithelium from patients with cancer (benign), high-grade dysplasia (HGD) tissue and squamous cell carcinoma (SCC) tissue

\begin{tabular}{|c|c|c|c|c|}
\hline \multirow[t]{2}{*}{ Markers categories } & \multirow[t]{2}{*}{ Tonsil controls $\mathrm{n}=37$} & \multicolumn{3}{|c|}{ Patients with SCC } \\
\hline & & Benign $\mathrm{n}=40$ & $H G D \mathrm{n}=26$ & $S C C \mathrm{n}=45$ \\
\hline \multicolumn{5}{|l|}{ Ki-67 (MIB 1) } \\
\hline Intensity & $0.05(0.33)$ & $0.23(0.70)$ & $1.65(1.45)^{\mathrm{a}, \mathrm{b}}$ & $2.50(0.74)^{\mathrm{a}, \mathrm{b}}$ \\
\hline Percent & $0.14(0.82)$ & $0.50(1.52)$ & $18.04(22.53)^{\mathrm{a}, \mathrm{b}}$ & $28.29(22.32)^{\mathrm{a}, \mathrm{b}}$ \\
\hline Combine & $0.27(1.64)$ & $1.13(3.49)$ & $52.67(67.18)^{\mathrm{a}, \mathrm{b}}$ & $76.98 \pm(66.89)^{a, b}$ \\
\hline \multicolumn{5}{|l|}{ EGFR } \\
\hline Intensity & $0.19(0.46)$ & $0.08(0.04)$ & $2.36(2.77)^{\mathrm{a}, \mathrm{b}}$ & $1.97(0.85)^{\mathrm{a}, \mathrm{b}}$ \\
\hline Percent & $2.57(6.83)$ & $2.63(10.57)$ & $60.86(33.28)^{\mathrm{a}, \mathrm{b}}$ & $69.11(32.39)^{a, b}$ \\
\hline Combine & $2.70(6.93)$ & $2.63(10.57)$ & $153.00(26.78)^{\mathrm{a}, \mathrm{b}}$ & $152.61(14.27)^{\mathrm{a}, \mathrm{b}}$ \\
\hline \multicolumn{5}{|l|}{$p$-Akt } \\
\hline Intensity & $0.91(0.66)$ & $1.32(0.76)$ & $2.77(0.38)^{\mathrm{a}, \mathrm{b}}$ & $2.80(0.39)^{\mathrm{a}, \mathrm{b}}$ \\
\hline Percent & 36.14 (36.38) & $52.82(25.06)$ & $86.92(10.50)^{\mathrm{a}, \mathrm{b}}$ & $90.14(12.05)^{a, b}$ \\
\hline Combine & $47.57(54.32)$ & $79.36(70.89)$ & $242.88(52.67)^{\mathrm{a}, \mathrm{b}}$ & $256.89(56.69)^{a, b}$ \\
\hline \multicolumn{5}{|l|}{$p-N F-\kappa B$} \\
\hline Intensity & $0.97(0.61)$ & $1.07(0.56)$ & $2.23(0.65)^{\mathrm{a}, \mathrm{b}}$ & $2.22(0.62)^{\mathrm{a}, \mathrm{b}}$ \\
\hline Percent & $42.10(34.49)$ & $51.32(26.83)$ & $80.00(16.00)^{a, b}$ & $76.36(22.94)^{a, b}$ \\
\hline Combine & $54.03(55.98)$ & $64.61(53.94)$ & $186.35(75.94)^{\mathrm{a}, \mathrm{b}}$ & $179.66(73.28)^{a, b}$ \\
\hline
\end{tabular}

Combine $=$ intensity $\times$ percent. EGFR $=$ epidermal growth factor receptor.

${ }^{\mathrm{a}} P$-value $<0.05$ as compared to tonsil controls.

${ }^{\mathrm{b}} P$-value $<0.05$ as compared to benign.

Values are presented as mean (s.d.). The overall ANOVA $P$-value was less than 0.001 for each marker.

Table 4 Percent (\%) distribution of intensity score of marker expression from patients without cancer (tonsil controls), benign squamous epithelium from patients with cancer (benign), highgrade dysplasia (HGD) tissue and squamous cell carcinoma (SCC) tissue

\begin{tabular}{|c|c|c|c|c|c|}
\hline \multirow[t]{2}{*}{ Groups } & \multirow[t]{2}{*}{ Markers } & \multicolumn{4}{|c|}{$\begin{array}{c}\text { Arbitrary scores of staining } \\
\text { intensity }\end{array}$} \\
\hline & & $\%$ of 0 & $\%$ of $1+$ & $\%$ of $2+$ & $\%$ of $3+$ \\
\hline \multirow{4}{*}{$\begin{array}{l}\text { Tonsil controls } \\
N=37\end{array}$} & Ki-67 & 97 & 0 & 3 & 0 \\
\hline & EGFR & 81 & 16 & 3 & 0 \\
\hline & p-Akt & 26 & 57 & 7 & 0 \\
\hline & $\mathrm{p}-\mathrm{NF}-\kappa \mathrm{B}$ & 16 & 68 & 16 & 0 \\
\hline \multirow[t]{4}{*}{ Benign $N=40$} & Ki-67 & 90 & 0 & 8 & 2 \\
\hline & EGFR & 92 & 8 & 0 & 0 \\
\hline & p-Akt & 5 & 82 & 5 & 8 \\
\hline & p-NF- $\kappa \mathrm{B}$ & 3 & 86 & 8 & 3 \\
\hline \multirow[t]{4}{*}{ HGD $N=26$} & Ki-67 & 40 & 0 & 12 & 48 \\
\hline & EGFR & 8 & 32 & 40 & 20 \\
\hline & p-Akt & 0 & 0 & 31 & 69 \\
\hline & p-NF- $\kappa$ B & 0 & 15 & 54 & 31 \\
\hline \multirow[t]{4}{*}{ SCC $N=45$} & Ki-67 & 4 & 2 & 38 & 56 \\
\hline & EGFR & 4 & 20 & 45 & 31 \\
\hline & p-Akt & 0 & 0 & 20 & 80 \\
\hline & $\mathrm{p}-\mathrm{NF}-\kappa \mathrm{B}$ & 2 & 23 & 65 & 20 \\
\hline
\end{tabular}

EGFR—epidermal growth factor receptors; p-NF- $\kappa \mathrm{B}$ - phospho-nuclear factor-kappa B; p-Akt-phospho-Akt.

between p-Akt expression and survival. An increase in one level of score, such as from $1+$ to $2+$, decreased the chance of survival by 3.7 -fold (hazard rate $=4.1,95 \% \mathrm{CI}=[1.0,14.5], P=0.043)$. Figure 4 (upper panel) contains the disease-free survival curve stratified by p-Akt level. There was no significant relationship between p-Akt and recurrence. There was a significant relationship between $\mathrm{p}-\mathrm{NF}-\kappa \mathrm{B}$ and survival. An increase in one level of score, such as from $1+$ to $2+$, decreased the chance of survival by 4.0-fold (hazard rate $=4.0,95 \%$ $\mathrm{CI}=[1.5,10.8], P=0.006$ ). Figure 4 (lower panel) contains the disease-free survival curve stratified by p-NF- $\kappa$ B level. In Figure 5, there was a significant relationship between p-NF- $\kappa$ B and recurrence (higher scores of $\mathrm{p}-\mathrm{NF}-\kappa \mathrm{B}$ related to greater chance of recurrence, $P=0.049$ ).

\section{Discussion}

Head and neck squamous cell carcinoma is characterized by local tumor aggressiveness, high rate of early recurrence (regional and distant) and development of second primary carcinomas. Despite modern therapeutic strategies like adjuvant and neoadjuvant radiotherapy and chemotherapy, in addition to surgical management of the tumor, the overall 5-year survival rate does not exceed $55 \% .^{18}$ Furthermore, head and neck squamous cell carcinoma is a heterogeneous group of tumors presenting in different anatomical regions such as the oral cavity, tonsils/pharynx and the larynx. These subentities show different, biological and clinical behavior, due to different genetic alterations. ${ }^{19}$ Head and neck squamous cell carcinoma of the oropharyngeal area 
930
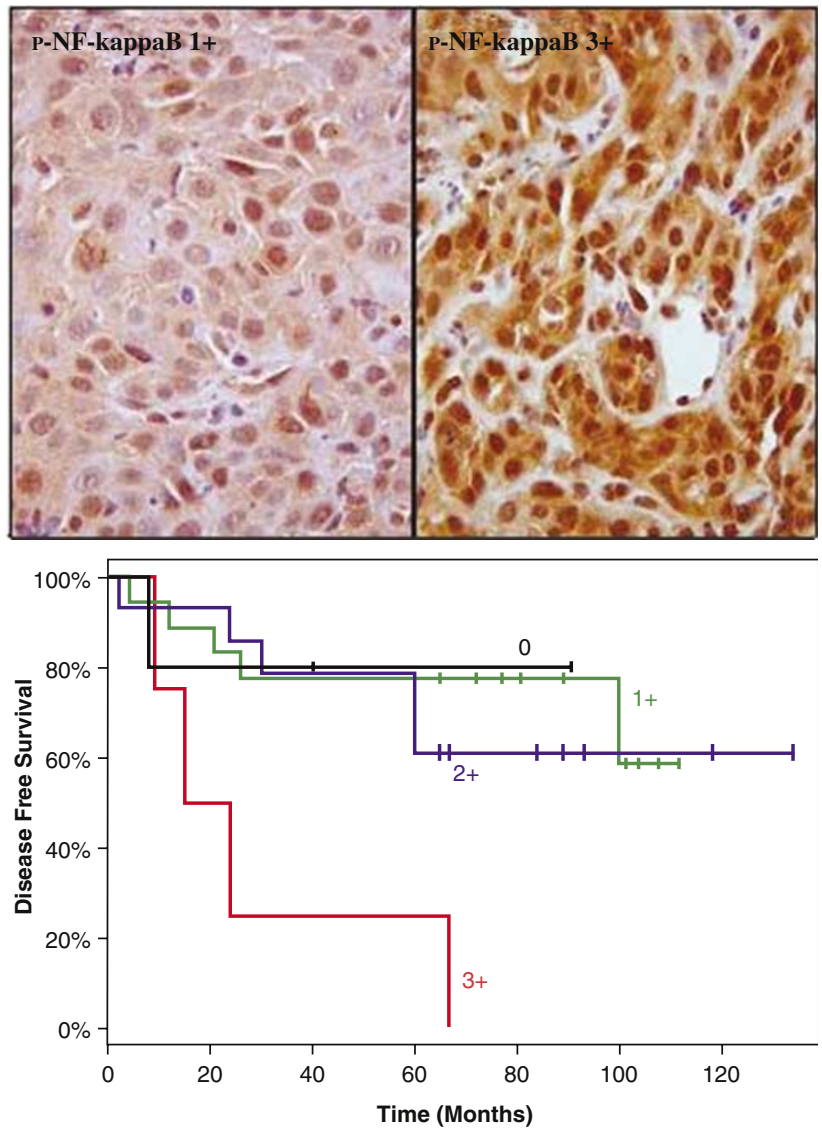

Figure 3 Upper panel: contrast $1+$ (left) and $3+$ (right) p-NF- $\kappa \mathrm{B}$ staining of tonsillar squamous cell carcinoma (magnification $\times 600$ ). Lower panel: disease-free survival curve (\%) stratified by $\mathrm{p}-\mathrm{NF}-\kappa \mathrm{B}$ level from tissue with tonsillar squamous cell carcinoma $(n=41 ; P=0.047)$.

has been related mainly to tobacco and alcohol abuse. $^{20,21}$ Our clinical data including survival, recurrence and tobacco use in the patients with squamous cell carcinoma of the tonsil are essentially compatible with reports in the literature.

Ki-67 was overexpressed in both high-grade dysplasia and squamous cell carcinoma of the tonsil as reported previously. ${ }^{22}$ Our data of overexpressed EGFR in squamous cell carcinoma of the tonsil are also consistent with other reports. ${ }^{1,2}$ In addition, we found that high-grade dysplasia was characterized statistically by overexpression of EGFR at the top $1 / 3$ of the squamous epithelium, which may be used as a morphoproteomic marker for confirming the highgrade dysplasia. Moreover, we found that p-Akt was highly expressed in squamous cell carcinoma of the tonsil, confirming one study reported in $2002^{23}$ and also in high-grade dysplasia. Several gene and protein studies provide evidence of an activated NF- $\kappa$ B pathway. ${ }^{7-9,24}$ Our morphoproteomic data indicate that $\mathrm{p}-\mathrm{NF}-\kappa \mathrm{B}$ is overexpressed and translocated to the nuclei in both high-grade dysplasia and squamous cell carcinoma of the tonsil, pointing toward an activated NF- $\kappa$ B pathway in head and neck squamous cell carcinoma. Taken together, our
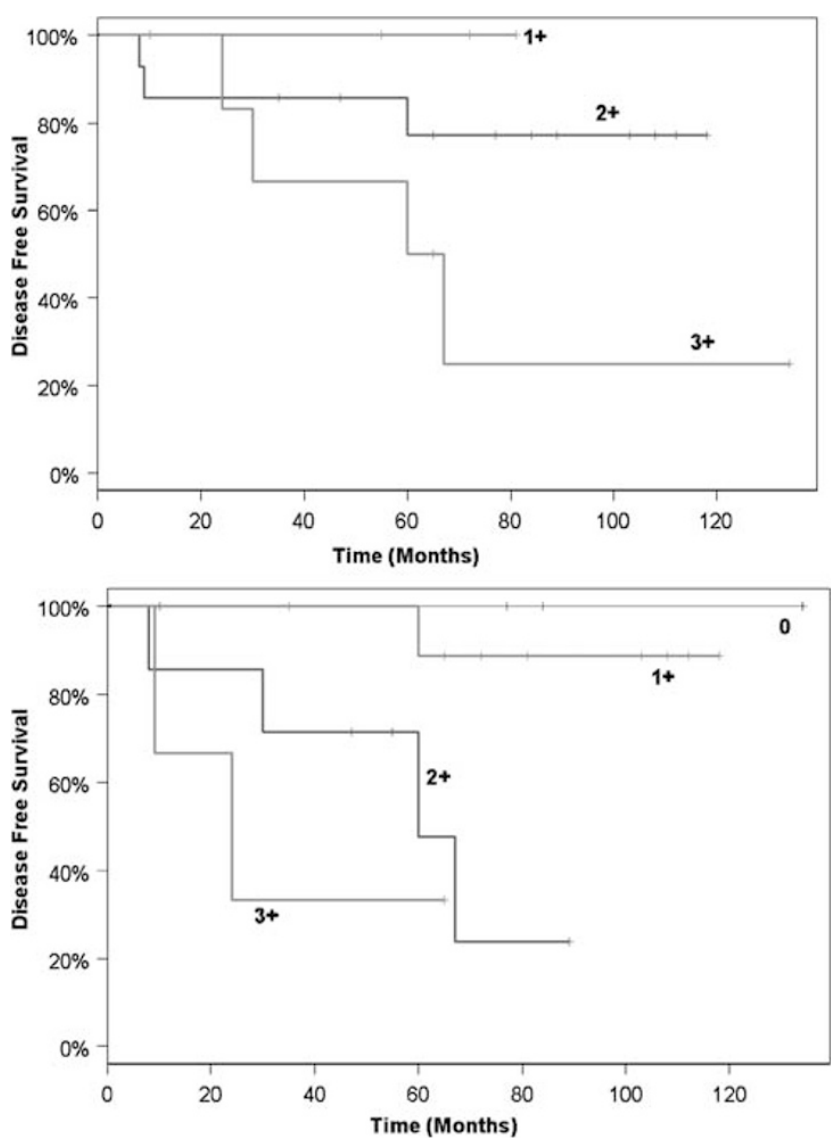

Figure 4 Disease-free survival curve (\%) stratified by p-Akt level from high-grade dysplasia $(n=29, P=0.043$; upper panel) and by p-NF- $\kappa$ B level from high-grade dysplasia $(n=29, P=0.006$; lower panel).

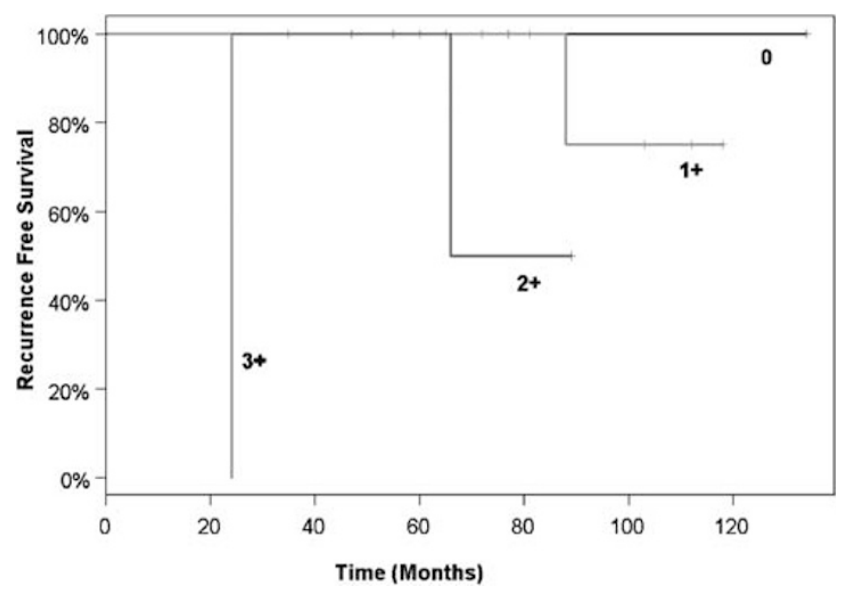

Figure 5 Recurrence-free survival curve (\%) stratified by p-NF- $\kappa \mathrm{B}$ level from high-grade dysplasia $(n=29, P=0.049)$.

data suggest that high-grade dysplasia possesses all the proliferative power along EGFR-Akt-NF- $\kappa$ B axes that occurs in squamous cell carcinoma of the tonsil. 
The most striking finding in the current study was that the $\mathrm{p}-\mathrm{NF}-\kappa \mathrm{B}$ overexpression in both high-grade dysplasia and squamous cell carcinoma was significantly associated with poor survival. Additionally, p-NF- $\kappa$ B from tissue with high-grade dysplasia was significantly related to tumor recurrence. Although there were fewer cases with high-grade dysplasia compared with squamous cell carcinoma of the tonsil, p-NF- $\kappa \mathrm{B}$ expression in high-grade dysplasia appears to carry a strong predictive value for both decreased survival and increased tumor recurrence in patients with squamous cell carcinoma of the tonsil. One speculation is that high-grade dysplasia is usually multifocal and may be more insidious when surgical margins are involved. Based on the data, it may be prudent to aggressively attempt to identify areas of high-grade dysplasia pathologically and implement treatment earlier in the course of managing these patients. The overexpressed p-Akt was significantly associated with poor survival in our study, consistent with a report that p-Akt expression is adversely associated with local control of head and neck squamous cell carcinoma.$^{23}$ In the current investigation, the correlation of EGFR overexpression with the survival rate of patients with squamous cell carcinoma of the tonsil, although suggestive, did not reach a statistical significance $(P=0.12)$, in contrast to what has been reported in a previous study. ${ }^{1}$ Furthermore, since TNM status and stage in this population of cancer patients were not significantly correlated with the clinical outcome; our data suggest that $\mathrm{p}-\mathrm{NF}-\kappa \mathrm{B}$ is potentially more sensitive than the conventional value of TNM status and stage to predict prognosis.

Identification of $\mathrm{p}-\mathrm{NF}-\kappa \mathrm{B}$ as a significant predictor for worse outcome also raises the possibility that p-NF- $\kappa$ B may be an important therapeutic target for clinical intervention. Activation of NF- $\kappa$ B has been correlated with radiation resistance in human head and neck squamous cell carcinoma. ${ }^{25}$ Using cultured head and neck squamous cell carcinoma from mice, a gene microarray study reports that increased activation of the NF- $\kappa \mathrm{B}$ pathway is accompanied by the altered expression of several genes that can regulate NF- $\kappa \mathrm{B} .{ }^{9}$ It is importantly noted that these altered genes include those responsible for proteasome function and I- $\kappa \mathrm{B}$ degradation such as ubiquitin-activating enzyme E1, Nedd-8 and LMP-7. Since a potent proteasome inhibitor, Velcade (bortezomib, formerly called PS-341), has been shown to inhibit tumor growth, partially achieved by inhibiting DNAbinding activity of NF- $\kappa \mathrm{B},{ }^{26,27}$ such an inhibitor may have potential in treating head and neck squamous cell carcinoma. Furthermore, p53 overexpression in head and neck squamous cell carcinoma has been associated with poor clinical outcome $\mathrm{e}^{28,29}$ and p53 appears to be an additional target for Velcade in several recent studies. ${ }^{30-32}$ Velcade, targeting both $\mathrm{NF}-\kappa \mathrm{B}$ and p53, may be potentially important in controlling the growth of head and neck squamous cell carcinoma. In addition, the staining intensity of $\mathrm{p}-\mathrm{NF}-\kappa \mathrm{B}$ and p53 may be used as markers for predicting drug effects of Velcade. Our recent study found good correlation between nuclear p-NF- $\kappa$ B staining and inhibitory effects of Velcade in breast cancer cell lines. ${ }^{33}$ Curcumin represents another potential therapeutic option in squamous cell carcinoma of the tonsil by virtue of its ability to inhibit the growth and survival of human head and neck squamous cell carcinoma cells via modulation of NF- $\kappa$ B signaling. ${ }^{34}$ The latter is accomplished through curcumin's ability to abrogate I- $\kappa \mathrm{B}$ alpha kinase (IKK), which is needed for NF- $\kappa \mathrm{B}$ activation. Curcumin is also attractive because of its apparent use and relative pharmacological safety in humans. ${ }^{34,35}$

In summary, this investigation demonstrated overexpression of EGFR, p-Akt and p-NF- $\kappa$ B for squamous cell carcinoma of the tonsil and associated high-grade dysplasia, as compared with adjacent non-neoplastic squamous epithelium and tonsillar controls. Overexpressed and translocated p-NF- $\kappa \mathrm{B}$ was a marker significantly related to poor prognosis in patients with high-grade dysplasia or squamous cell carcinoma of the tonsil.

\section{Acknowledgements}

The study was financially supported by an intramural grant of Geisinger Health System. We thank Ms Laurie Kneller, HT (ASCP), Ms Tina Brosius, HT (ASCP) and Mr Glen Kauwell, HT (ASCP) for their technical assistance, and Ms Sharon Coup for her secretarial support.

\section{References}

1 Chen I-H, Chang JT, Liao C-T, et al. Prognostic significance of EGFR and HER-2 in oral cavity cancer in betel quid prevalent area. Br J Cancer 2003;89: 681-686.

2 Nguyen DC, Parsa B, Close A, et al. Overexpression of cell cycle regulatory proteins correlates with advanced tumor stage in head and neck squamous cell carcinomas. Int J Oncol 2003;22:1285-1290.

3 Cohen EE, Rosen F, Stadler WM, et al. Phase II trial of ZD1839 in recurrent or metastatic squamous cell carcinoma of the head and neck. J Clin Oncol 2003; 21:1980-1987.

4 Chun K-H, Lee H-Y, Hassan K, et al. Implication of protein kinases B/Akt and Bcl-2/BcloxL suppression by the farnesyl transferase inhibitor SCH66336 in apoptosis induction in squamous carcinoma cells. Cancer Res 2003;63:4796-4800.

5 Nakayama H, Ikebe T, Beppu M, et al. High expression levels of nuclear factor $\kappa \mathrm{B}$, I $\kappa \mathrm{B}$ kinases $\alpha$ and Akt kinase in squamous cell carcinoma of the oral cavity. Cancer 2001;92:3037-3044.

6 Ondrey FG, Dong G, Sunwoo J, et al. Constitutive activation of transcription factor NF- $\kappa \mathrm{B}, \mathrm{AP}-1$, and NFLI6 in human head and neck squamous cell carcinoma 
cell lines that express pro-inflammatory and proangiogenic cytokines. Mol Carcinog 1999;26:119-129.

7 Tamatani T, Azuma M, Aota K, et al. Enhanced $\mathrm{I} \kappa \mathrm{B}$ kinase activity is responsible for the augmented activity of NF- $\kappa \mathrm{B}$ in human head and neck carcinoma cells. Cancer Lett 2001;17:165-172.

8 Chen Z, Zhang K, Zhang X, et al. Comparison of gene expression between metastatic derivatives and their poorly metastatic parental cells implicates crucial tumor-environment interaction in metastasis of head and neck squamous cell carcinoma. Clin Exp Metastasis 2003;20:335-342.

9 Dong G, Loukinova E, Chen Z, et al. Molecular profiling of transformed and metastatic murine squamous carcinoma cells by differential display and cDNA microarray reveals altered expression of multiple genes related to growth, apoptosis, angiogenesis, and the NF- $\kappa$ B signal pathway. Cancer Res 2001;61: 4797-4808.

10 Cooper JA, Bowen-Pope DF, Raines E, et al. Similar effects of platelet-derived growth factor and epidermal growth factor on the phosphorylation of tyrosine in cellular proteins. Cell 1982;31:263-272.

11 Hunter T, Ling N, Copper JA. Protein kinase C phosphorylation of the EGF receptor at a threonine residue close to the cytoplasmic face of the plasma membrane. Nature 1984;311:480-483.

12 Mitsiades CS, Mitsiades N, Koutsilieris M. The Akt pathway: molecular targets for anti-cancer drug development. Curr Cancer Drug Targets 2004;4:235-256.

13 Clemens MJ. Targets and mechanisms for the regulation of translation in malignant transformation. Oncogene 2004;23:3180-3188.

14 Lu Z, Jiang G, Blume-Jensen P, et al. Epidermal growth factor-induced tumor cell invasion and metastasis initiated by dephosphorylation and downregulation of focal adhesion kinase. Mol Cell Biol 2001;21:4016-4031.

15 Sun W, Zhang PL, Herrera GA. p53 protein and Ki-67 overexpression in urothelial dysplasia of bladder. Appl Immunohistochem Mol Morphol 2002;10:327-331.

16 Brown RE, Lun M, Prichard JW, et al. Morphoproteomic and pharmacoproteomic correlates in hormonereceptor-negative breast carcinoma cell lines. Ann Clin Lab Sci 2004;34:251-262.

17 Maidhof R, Prantl F, Hornstein OP, et al. Some measures of proliferative activity in normal and leukoplakic buccal mucosa. Arch Dermatol Res 1977; 260:193-200.

18 Landis SH, Murray T, Bolden S, et al. Cancer statistics. CA Cancer J Clin 1999;49:8-31.

19 Poetsch M, Kleist B, Lorenz G, et al. Different numerical chromosomal aberrations detected by FISH in oropharygeal, hypopharyngeal and laryngeal squamous cell carcinoma. Histopathology 1999;34: 234-240.

20 Binnie WH, Rankin KV. Epidermiological and diagnostic aspects of oral squamous cell carcinoma. J Oral Pathol 1984;13:333-341.

21 Forastiere A, Koch W, Trotti A, et al. Head and neck cancer. N Eng J Med 2001;345:1890-1900.
22 Coltrera MD, Zarbo MJ, Sakt WA, et al. Markers for dysplasia of the upper aerodigestive tract. Suprabasal expression of PCNA, p53 and CK19 in alcoholfixed, embedded tissue. Am J Pathol 1992;141: 817-825.

23 Gupta AK, McKenna WG, Weber CN, et al. Local recurrence in head and neck cancer: relationship to radiation resistance and signal transduction. Clin Cancer Res 2002;8:885-892.

24 Bancroft CC, Chen Z, Dong G, et al. Coexpression of proangiogenic factor IL-8 and VEGF by human head and neck squamous cell carcinoma involves coactivation by MEK-MAPK and IKK-NF- $\kappa$ B signal pathway. Clin Cancer Res 2001;7:435-442.

25 Kato T, Duffey DV, Ondrey FG, et al. Cisplatin and radiation sensitivity in human head and neck squamous carcinomas are independently modulated by glutathione and transcription factor NF-kappaB. Head Neck 2000;22:748-759.

26 Adams J, Palombella VJ, Sausville EA, et al. Proteasome inhibitors: a novel class of potent and effective antitumor agents. Cancer Res 1999;59:2615-2622.

27 Pham LV, Tamayo AT, Yoshimura LC, et al. Inhibition of constitutive NF- $\kappa \mathrm{B}$ activation in mantle cell lymphoma B cell leads to induction of cell cycle arrest and apoptosis. J Immunol 2003;171:88-95.

28 Carlos de Vicente J, Junquera Gutierres LM, Zapatero $\mathrm{AH}$, et al. Prognostic significance of p53 expression in oral squamous cell carcinoma without neck node metastasis. Head Neck 2004;26:22-30.

29 Pukkila MJ, Kumpulainen EJ, Virtaniemi JA, et al. Nuclear and cytoplasmic p53 expression in pharyngeal squamous cell carcinoma: prognostic implications. Head Neck 2002;24:784-791.

30 Williams SA, McConkey DJ. The proteasome inhibitor Bortezomib stabilizes a novel active form of p53 in human LNCaP prote5 prostate cancer cells. Cancer Res 2003;63:7338-7344

31 Yu J, Tiwari S, Steiner P, et al. Differential apoptotic response to the proteasome inhibitor Bortezomib (Velcade, PS341) in Bax-deficient and p21-difficient colon cancer cells. Cancer Biol Ther 2003;2:694-699.

32 An WG, Hwang S-G, Trepel JB, et al. Protease inhibitorinduced apoptosis: accumulation of wt p53, p21WAF1/CIP1, and induction of apoptosis are independent markers of proteasome inhibition. Leukemia 2000;14:1276-1283.

33 Lun M, Siegelmann-Danieli N, Karosas BA, et al. In vitro inhibitory effects of Velcade (bortezomib) in breast cancer lines can be correlated with morphoproteomic analysis of p-NF-kappaB. Proc Am Assoc Cancer Res 2004;45:424-425.

34 Aggarwal S, Takada Y, Singh S, et al. Inhibition of growth and survival of human head and neck squamous cell carcinoma cells by curcumin via modulation of nuclear factor-kappaB signaling. Int J Cancer 2004;111:679-692.

35 Rasyid A, Rahman AR, Jaalam K, et al. Effect of different curcumin dosages on human gall bladder. Asia Pac J Clin Nutr 2002;11:314-318. 